\title{
Estudos químicos e atividades farmacológicas de espécies pertencentes ao gênero Byrsonima: uma revisão integrativa
}

\author{
Chemical studies and pharmacological activities of species belonging to the Byrsonima genus: an \\ integrative review
}

Estudios químicos y actividades farmacológicas de especies del género Byrsonima: una revisión integrativa

\section{Resumo}

O presente estudo teve como objetivo integrar os resultados de diferentes estudos químicos e farmacológicos de espécies pertencentes ao gênero Byrsonima. A busca dos artigos foi realizada por meio de três bases de dados (SCOPUS, MEDLINE, PUBMED), onde se utilizou as strings "Byrsonima AND medicine pharmaceutical" nos últimos 5 anos. Além disso, foi pesquisado nos periódicos Capes, sem limitação do período. Foram encontrados 65 artigos em que foram submetidos a leitura de títulos e resumos. Na etapa seguinte, 30 artigos foram lidos por completo, excluindo-se os que não tinham nenhuma relação com o tema. As seguintes informações foram coletadas nos artigos: caracterização química, substâncias isoladas, resultados dos estudos farmacológicos. Ao final, 24 artigos puderam ser incluídos nesta revisão e tratavam de estudos químicos e/ou farmacológicos. A atividade antioxidante foi relatada para diferentes espécies de Byrsonima, utilizando diferentes métodos de análises. Também, mostraram-se promissoras para as atividades anti-inflamatória e antinoceptivo. As atividades antioxidante, anti-inflamatória e analgésica, das espécies pertencentes a este gênero, têm sido relacionadas aos compostos fenólicos, em especial aos flavonoides. Além destas atividades, espécies de Byrsonima parecem promissoras como gastroprotetora, antituberculose e antiparasitária. Os estudos que avaliaram a toxicidade são escassos, sendo incluído apenas 2 artigos que demonstraram que as diferentes espécies possuem potencial citotóxico. Desse modo, é possível identificar e sintetizar as atividades presentes nas espécies do gênero, de maneira a facilitar estudos futuros.

Palavras-chave: Byrsonima; Polifenois; Flavonoides; Anti-inflamatório; Antioxidante; Analgésico.

\begin{abstract}
The present study aimed to integrate the results of different chemical and pharmacological studies of species belonging to the genus Byrsonima. The search for articles was performed through three databases (SCOPUS, MEDLINE, PUBMED), where the strings "Byrsonima AND medicine pharmaceutical" were used in the last 5 years. In addition, it was researched in Capes journals, without period limitation. Sixty-five articles were found in which titles and abstracts were read. In the next step, 30 articles were read in full, excluding those that had no relation to the topic. The following information was collected from the articles: chemical characterization, isolated substances, results of pharmacological studies. In the end, 24 articles could be included in this review and dealt with chemical
\end{abstract}


and/or pharmacological studies. Antioxidant activity was reported for different species of Byrsonima, using different methods of analysis. Also, they showed promise for anti-inflammatory and antinociceptive activities. Antioxidant, anti-inflammatory, and analgesic activities of species belonging to this genus have been related to phenolic compounds, especially flavonoids. In addition to these activities, species of Byrsonima seem to be promising as gastroprotective, antituberculosis, and antiparasitic. The studies that evaluated the toxicity are scarce, being included only 2 articles that demonstrated that the different species have cytotoxic potential. This way, it's possible to identify and synthesize the activities present in the species of the genus, in order to facilitate future studies.

Keywords: Byrsonima; Polyphenols; Flavonoids; Anti-inflamatory; Antioxidant; Analgesic.

\section{Resumen}

El presente estudio tuvo como objetivo integrar los resultados de diferentes estudios químicos y farmacológicos de especies pertenecientes al género Byrsonima. La búsqueda de artículos se realizó a través de tres bases de datos (SCOPUS, MEDLINE, PUBMED), donde se utilizaron las cadenas "Byrsonima Y medicina farmacéutica" en los últimos 5 años. Además, se investigó en las revistas Capes, sin límite de tiempo. Se encontraron sesenta y cinco artículos en los que se leyeron títulos y resúmenes. En el siguiente paso, se leyeron 30 artículos en su totalidad, excluyendo aquellos que no tenían relación con el tema. De los artículos se recogió la siguiente información: caracterización química, sustancias aisladas, resultados de estudios farmacológicos. Al final, se podrían incluir 24 artículos en esta revisión que trataran de estudios químicos y/o farmacológicos. Se informó la actividad antioxidante para diferentes especies de Byrsonima, utilizando diferentes métodos de análisis. Además, se mostraron prometedores para las actividades antiinflamatorias y antinoceptivas. Las actividades antioxidantes, antiinflamatorias y analgésicas de especies pertenecientes a este género se han relacionado con compuestos fenólicos, especialmente flavonoides. Además de estas actividades, las especies de Byrsonima parecen prometedoras como gastroprotectoras, antituberculosas y antiparasitarias. Los estudios que evaluaron la toxicidad son escasos, incluyéndose solo 2 artículos que demostraron que las diferentes especies tienen potencial citotóxico. De esta forma, es posible identificar y sintetizar las actividades presentes en las especies del género, con el fin de facilitar futuros estudios.

Palabras clave: Byrsonima; Polifenoles; Flavonoides; Antiinflamotorio; Antioxidante; Analgésico.

\section{Introdução}

O gênero Byrsonima é um dos maiores gêneros da família Malpighiaceae, possuindo aproximadamente 150 espécies catalogadas com ocorrências amplamente registrada pela América tropical, podendo ocorrer desde o Caribe até a Argentina (Alexadrino, et al., 2011). Este gênero é caracterizado por plantas dicotiledônias que em sua maioria apresentam um tronco tortuoso de casca espessa, folhas simples concentradas em direção as extremidades dos ramos e de frutos amarelos arredondados. Frutos esses que são comestíveis e bastante apreciados pela população, podendo ser consumido in natura ou como sucos, geleias, entre outros (Reflora, 2020).

São espécies nativas do Brasil e se distribuem em biomas brasileiros, principalmente, na Amazônia, Catinga e Cerrado. No Brasil, ocorrem mais de 50 espécies deste gênero (Reflora, 2020), dentre estas, algumas tem uma importância medicinal, como por exemplo, a B. crassifólia e B. verbascifolia.

As populações utilizam os frutos, folhas e cascas do caule das espécies de Byrsonima com fins medicinais. O infuso das folhas de B. verbascifolia é usado para o tratamento de diarreia, infecção intestinal e proteção da mucosa intestinal, enquanto que a infusão de raízes para o tratamento de feridas crônicas, inflamação da cavidade oral e da garganta e do trato genital feminino (Saldanha \& Soares, 2015). Outra espécie, B. intermedia, possui as seguintes alegações de uso popular: tratamento de disenteria, diarreia, dores estomacais, asma, infecções cutâneas, tuberculose, febre e como diurético (Santos 2019).

De espécies do gênero Byrsonima já foram isolados compostos fenólicos e terpenos (Guilhon-Simplício \& Pereira, 2011). Alguns estudos demonstraram as atividades anti-inflamatória (Saldanha, et al., 2015), gastroprotetora (Bonacorsi, et al., 2013), antioxidante (Peraza-Sanchez, et al., 2005; Pereira, et al., 2015; Vargas, et al., 2016; Verdam, et al., 2017; GuilhonSimplicio, et al., 2017; Santos, et al., 2017; Souza, et al., 2017; Santos, et al., 2019; Silva, et al., 2019; Belisário, et al., 2020; Souza-Melo, et al., 2021) e antimicrobiana (Higuchi, et al., 2011). 
A presente revisão integrativa visa avaliar os resultados dos estudos químicos e farmacológicos, visando verificar se estes estudos validam o uso popular, bem como quais são os possíveis compostos envolvidos nestas atividades. Por fim, se o possível mecanismo de ação do composto já foi elucidado.

\section{Metodologia}

Neste estudo foi utilizado o método comparativo, do tipo quali-quantitativo sendo feitas buscas em bases de dados (Pereira, et al., 2018), acerca do gênero Byrsonima spp onde seus diferentes resultados foram relacionados com seu potencial medicinal e farmacológico. As bases de dados utilizadas na pesquisa foram SCOPUS, MEDLINE e PUBMED (Cruz et al., 2020). Por meio do uso das strings "Byrsonima AND medicine pharmaceutical" puderam ser encontrados 169 artigos, 31 na plataforma SCOPUS, 19 na plataforma MEDLINE, 10 na plataforma PUBMED e 109 na Capes. Ressalta-se que apenas na Capes não houve limitação de anos e nas demais bases pesquisou-se apenas entre 2015-2020.

Como critério de inclusão adotou-se: todos os artigos deveriam ter sido revisados por pares; ter sido publicados em revistas revisadas por pares, abordar, pelo menos, composição química ou alguma atividade farmacológica de alguma espécie de Byrsonima. Foram excluídos artigos que continham Byrsonima apenas nas citações ou estavam presentes nas referências; artigos que não apresentassem relevância farmacológica.

Inicialmente foi feita leitura do título e resumo, seguida de exclusão dos artigos que não se adequassem nos critérios de inclusão, ao final desta etapa 30 artigos foram selecionados (SCOPUS=4, MEDLINE=3, PUBMED=10, Capes=13). Depois dessa triagem inicial, os artigos foram todos lidos na íntegra e coletadas seguintes informações: composição química e atividades farmacológicas e síntese dos resultados. Após aplicação de todos os critérios, em conjunto os autores decidiram incluir permanentemente 24 artigos para a realização do estudo. Abaixo, tem-se o fluxograma com a síntese do protocolo adotado neste trabalho (Figura 1).

Figura 1: Fluxograma da seleção dos artigos.

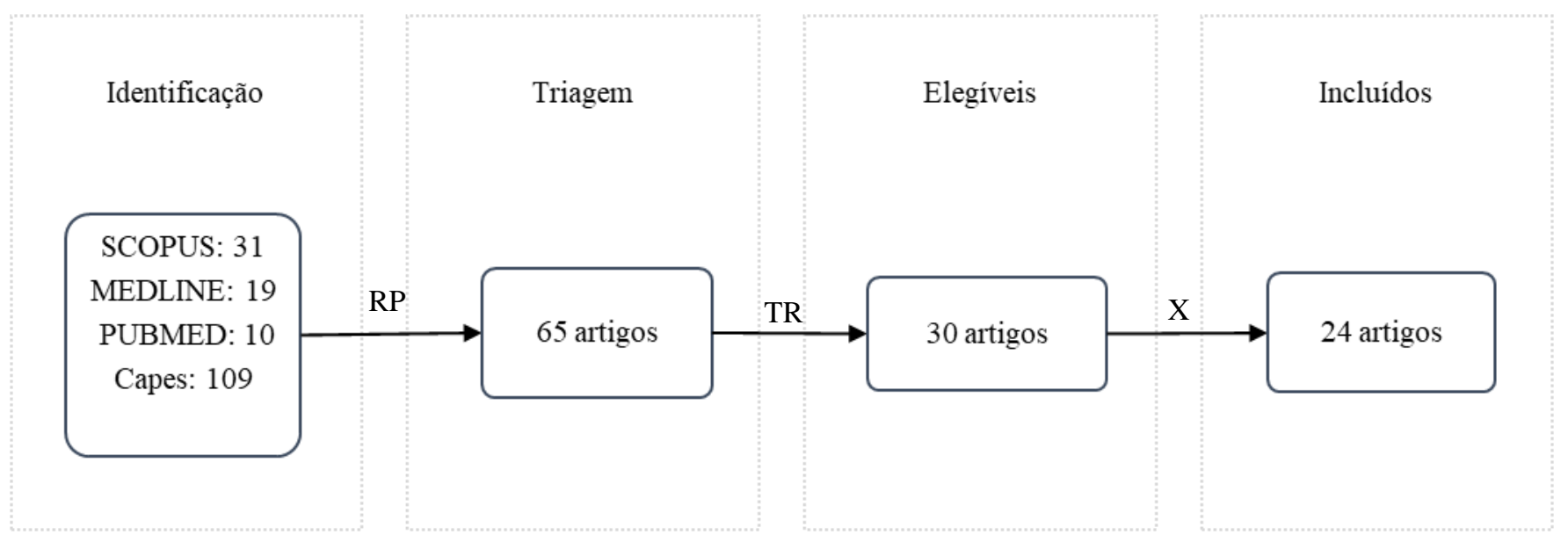

Legenda: RP: Revisados por pares. TR: Leitura de títulos e resumos. X: Leitura do artigo na íntegra. Fonte: Autores

\section{Resultados e Discussão}

Nesta revisão foram incluídos vinte e três artigos, de diferentes periódicos científicos (Tabela 1), sendo que estes envolviam estudos químicos (7 artigos), atividade antioxidante (10 artigos), anti-inflamatória (7 artigos), manejo da dor (5 artigos), tratamento da gastrite (2 artigos), antiparasitário (3 artigos), antituberculose (1 artigo) e antifúngicos (1). Poucos 
artigos avaliaram o potencial tóxico das espécies pertencentes ao gênero Byrsonima, tendo sido encontrados apenas 3 artigos de avaliação da citotoxicidade ou mutagenicidade (Tabela 2).

As espécies do gênero Byrsonima comumente apresentam compostos fenólicos como flavonas, flavonóis, ácido gálico entre outros (Sannomiya, et al., 2007; Saldanha, et al., 2016). A presença destes compostos indica potencial atividade antioxidante e anti-inflamatória dessas espécies. Os polifenóis, em especial os flavonoides, possuem características estruturais que permitem o sequestro de radicais, tais como: reatividade como agente doador de $\mathrm{H}$ e elétrons, capacidade de quelar metais de transição e presença de hidroxilas (Barreiros, et al., 2000). Entre os flavonoides didroxilados, os flavonoides com maior potencial antioxidante possuem um sistema catecol (3',4'-didroxi) no anel B. Também, flavonoides com múltiplas hidroxilas como, por exemplo a quercetina (Saldanha, et al., 2016 , Saldanha, et al., 2016 ${ }^{\mathrm{b}}$ ), possuem elevada atividade antioxidante (Yang, et al., 2001). A presença destes metabólitos nas espécies pode explicar o número elevado de estudos que tem como foco a atividade antioxidante (Peraza-Sanchez, et al., 2005; Pereira, et al., 2015; Vargas, et al., 2016; Verdam, et al., 2017; Guilhon-Simplicio, et al., 2017; Santos, et al., 2017; Souza, et al., 2017; Santos, et al., 2019; Silva, et al., 2019; Belisário, et al., 2020; Souza-Melo, et al., 2021).

Aos flavonoides tem sido atribuído a atividade anti-inflamatória de diferentes espécies vegetais e parece que vários mecanismos possam estar envolvidos nesta atividade, como: inibição da síntese de TNF- $\alpha$; bloqueio da fosfolipase (Agnihotri, Wakode \& Agnihot, 2010), COX 1, COX- 2, lipoxigenases (Agnihotri et al., 2010; Barros, 2012); redução da adesão de células inflamatórias ao endotélio vascular (Barros, 2012); inibição da elastase neutrofílica humana (HNE) e as metaloproteinases da matriz; inibição da oxido nítrico sintase (NOS), supressão da iNOS (Agnihotri et al., 2010; Moraes, 2011), supressão da ativação da ERK e p38MAP quinase (Cho, et al., 2003). De modo similar a atividade antioxidante, acredita-se que a atividade anti-inflamatória está relacionada aos compostos fenólicos, em especial aos flavonoides (Taofiq, et al., 2016).

Vários estudos têm relacionado o efeito analgésico aos flavonoides (Cechinel Filho, et al., 1996; Cechinel Filho, et al., 2000; Da Silva, et al., 2001) e a atividade antinoceptiva das espécies pertencentes ao gênero Byrsonima pode estar relacionada, pelo menos em parte, a estes metabolitos (Kim, et al., 2004). Os flavonoides podem inibir a enzima óxido nítrico sintase tipo 2, envolvida na síntese de óxido nítrico (NO), ao inibir esta enzima bloqueiam as vias da cicloxigenase e/ou lipoxigenase (Robak et al., 1998), também da proteína quinase C e L-arginina/NO (Meotti et al., 2006). Vale ressaltar que essas vias estão envolvidas nas atividades anti-inflamatória (Kim et al., 2004) e antinociceptiva (Machelska et al., 1997). 
Tabela 1: Periódicos incluídos na presente revisão.

\begin{tabular}{|c|c|c|c|c|}
\hline Periódico & Área & Ano de Publicação & Classificação* $^{*}$ & Fator de Impacto \\
\hline Pharmaceutical Biology & Produtos naturais & 2005 e 2009 & $\mathrm{~B} 2$ & $3.503-\mathrm{Q} 1(2020)$ \\
\hline Journal of Plant Interactions & Produtos naturais & 2007 & $\mathrm{~B} 2$ & $4.208-\mathrm{Q} 1(2020)$ \\
\hline Journal of Ethnopharmacology & Ciências da vida e Multidisciplinaridade & 2007 e 2011 & $\mathrm{~A} 2$ & $2.000(2020)$ \\
\hline $\begin{array}{l}\text { Evidence-Based Complementary and Alternative } \\
\text { Medicine }\end{array}$ & Medicina complementar e alternativa & 20011 e 2013 & $\mathrm{~B} 2$ & $2.629(2021-2022)$ \\
\hline Parasitology Research & Parasitologia & 2012 & B3 & $2.289(2020)$ \\
\hline Natural Product Research & Química de produtos naturais & 2015 & $\mathrm{~B} 2$ & $2.862-\mathrm{Q} 2(2020)$ \\
\hline BMC Complementary and Alternative Medicine & Ciência, Tecnologia, Engenharia e Medicina & 2016 & $\mathrm{~B} 1$ & $2.833(2020)$ \\
\hline Cytotechnology & Cultura de células em sistemas in vitro & 2016 & $\mathrm{~B} 2$ & $2.058(2020)$ \\
\hline International Immunopharmacology & $\begin{array}{l}\text { Imunologia, farmacologia, biologia de citocinas, } \\
\text { imunoterapia, imunopatologia e imunotoxicologia }\end{array}$ & 2016 & B1 & $4.932(2020)$ \\
\hline Journal of natural medicines & Farmacognosia & 2016 & $\mathrm{~B} 2$ & $2.343(2020)$ \\
\hline Inflammopharmacology & Inflamação e farmacologia da dor & 2017 & $\mathrm{~B} 1$ & $4.473(2020)$ \\
\hline The Scientific World Journal & Ciência, Tecnologia e Medicina & 2017 & B3 & $2.400(2020)$ \\
\hline Phytotherapy Research & Produtos naturais & 2017 & $\mathrm{~B} 1$ & $5.878(2021-2022)$ \\
\hline Food Chemistry & Química e Bioquímica dos Alimentos & 2017 & A1 & $7.514(2020)$ \\
\hline Industrial Crops and Products & Plantas cultivadas de interesse industrial & 2017 & $\mathrm{~A} 2$ & $5.645(2020)$ \\
\hline Plant Foods for Human Nutrition & Ciência e tecnologia alimentar & 2019 & $\mathrm{~B} 1$ & $3.921(2020)$ \\
\hline Biomedicen \& Pharmacotherapy & Medicina clínica/básica e farmacologia & 2019 & $\mathrm{~B} 1$ & $6.529(2020)$ \\
\hline Ciência Rural & Ciências agrárias & 2020 & B3 & - \\
\hline Archives of Oral Biology & Ciências orais e craniofaciais & 2021 & $\mathrm{~B} 2$ & $2.52(2020)$ \\
\hline
\end{tabular}

*Informações colhidas com base na Plataforma Sucupira no quadriênio 2013-2016. Fonte: Autores. 
Tabela 2: Artigos incluídos na presente revisão.

\section{Título do Trabalho}

1- Screening of Native Plants from Yucatan for Anti-Giardia lamblia Activity.

2- In vitro allelopathic effects of extracts and amenthoflavone from Byrsonima crassa (Malpighiaceae).

3- Mutagenic evaluation and chemical investigation of Byrsonima intermedia A. Juss. leaf extracts.

4- Screening of plant extracts from the Brazilian Cerrado for their in vitro trypanocidal activity.

5- Anti-inflammatory and antinociceptive effects of the stem bark of Byrsonima intermedia A. Juss.

6- Anti-inflammatory effect of extract and fractions from the leaves of Byrsonima intermedia A. Juss. in rats.

7- Byrsonima fagifolia Niedenzu Apolar Compounds with Antitubercular Activity.

8- In vitro and in vivo trypanocidal activity of native plants from the Yucatan Peninsula.

9- Comparison of Brazilian Plants Used to Treat Gastritis on the Oxidative Burst of Helicobacter pylori-Stimulated Neutrophil.

10- Phytochemical screening, total phenolic content and antioxidant activity of Byrsonima species.

11- Antioxidant activity and peroxidase inhibition of Amazonian plants extracts traditionally used as anti-inflammatory.

12- LDH, proliferation curves and cell cycle analysis are the most suitable assays to identify and characterize new phytotherapeutic compounds.

13- Cytotoxic potential of selected medicinal plants in northeast Brazil.

14- Anti-inflammatory effects of the butanolic fraction of Byrsonima verbascifolia leaves: Mechanisms involving inhibition of tumor necrosis factor alpha, prostaglandin E2 production and migration of polymorphonuclear leucocyte in vivo experimentation.

15- Chemical composition and anti-inflammatory activity of the leaves of Byrsonima verbascifolia.

16- Peripheral and central antinociceptive effects of the butanolic fraction of Byrsonima verbascifolia leaves on nociception-induced models in mice.

17- Analgesic, Anti-Inflammatory, and Antioxidant Activities of Byrsonima duckeana W. R. Anderson (Malpighiaceae).

18- Chemical Composition and Antioxidant, Antinociceptive, and Anti-inflammatory Activities of Four Amazonian Byrsonima Species.

19- Nutraceutical potential of Byrsonima cydoniifolia fruits based on chemical composition, anti-inflammatory, and antihyperalgesic activities.

20- Byrsonima crassifolia extract and fraction prevent UVB-induced oxidative stress in keratinocytes culture and increase antioxidant activity on skin.

21- Volatile Compounds Determined by SPME-GC, Bioactive Compounds, In vitro Antioxidant Capacity and Physicochemical Characteristics of Four Native Fruits from South America.

22- Byrsonima intermedia A. Juss partitions promote gastroprotection against peptic ulcers and improve healing through antioxidant and antiinflammatory activities.

23- Carotenoids, sugars, ascorbic acid, total phenolic, and antioxidant activity of murici from Brazilian Cerrado during refrigerated storage.

24- Phytochemistry, antifungal and antioxidant activity, and cytotoxicity of Byrsonima gardneriana (A. Juss) extract.

\section{Tipo de estudo}

Anti-giardia

Fitoquimica

Mutagenicidade

Tripanossomicida

Anti-inflamatório e analgésico

Anti-inflamatório

Antituberculose

Tripanossomicida

Tratamento de gastrite

Antioxidante, Fitoquímica

Antioxidante

Citotoxicidade

Citotoxicidade

Anti-inflamatório

Anti-inflamatório, Fitoquímica

Antinociceptiva central e periférica

Analgésico, anti-inflamatório e antioxidante Fitoquímica, antioxidante, antinociceptiva e antiinflamatório

Antioxidante, anti-hiperalgésica, fitoquímica

Antioxidante

Antioxidante, fitoquímica

Tratamento da gastrite, antioxidante e antiinflamatória

Antioxidante, fitoquímica

Fitoquímica, antifúngica e antioxidante

Source: Authors. 


\subsection{Estudos químicos}

Do extrato metanólico das folhas $B$. verbascifolia foram identificados 42 compostos, dentre estes: ácido quinico (1a), ácido gálico (3), epicatequina (5), rutina (9), quercetina 3-O-robonobiosideo (10), quercetina 3-O-galactosideo (11), quercetina-O-galloil- pentosideo (13a), quercetina-O-hexose-galloil (13b), procianidina (32), dímero de procianidina tipo B (33), protocianidina dimérica esterificada com o ácido gálico (B2-3"-O-galato) (37) e quercertina-3-O-arabinosideo (38) (Saldanha, et al., 2016; Figura 2).

No extrato etanólico das folhas de $B$. crassifólia foram detectados os seguintes metabólitos: 3,5 , epigallocatequina gallato (6), catequina (7), e um glicosídeo de flavonol (quercetina 3-O- $\beta$-D-glicopiranosideo (13c)) (Souza, et al., 2017). O extrato de metanol $B$. intermedia foi detectado esteroide, flavonoide e tanino. Também foram identificados flavonoides: quercetina (8), quercetina-3-O-(2"-O-galoil)- $\beta$-galactopiranosídeo (37b) e quercetina-3-O-(2"-O-galoil)- $\alpha$-arabinopiranosídeo (37a; Sannomiya, et al., 2007; Figura 2).

Do extrato clorofórmico B. fagifolia foram isolados: Lupeol (15), $\beta$-amirina (16), $\beta$-amirina acetato (17), ácido básico (18), $\alpha$-amirina (19), e $\alpha$-amirina acetato (20) (Higuchi, et al., 2011). No extrato etanólico B. gardneriana foram identificados, principalmente, eucaliptol (14), ácido piroglutâmico (34) e ácido octanóico (35) (Souza-Melo, et al., 2021; Figura 2).

Outro estudo avaliou a composição química de B. crispa, sendo identificados as moléculas 1a, ácido cafeico (2), 3, ácido 4-hidroxibenzoico (4), 8, 9, galocatequina (21), naringenina (22), procianidina A2 (25) e mistura de catequina (30a e 30b). A composição química $B$. duckeana é bem parecida com a B. crispa, tendo sido detectados as moléculas 1, 2, 3, 8, 9 e 22 . Além disso, foram identificados na B. duckeana as moléculas 4, Campferol (23), isoramnetina (24) e ácido siríngico (31). A $B$. garciabarrigae foram isoladas as substâncias $1 \mathrm{a}, 2,3,4,8,9,21,22,24$ e 25. Um menor número de metabólitos foi identificado na B. incarnata, sendo relatados a presença das moléculas 1a, 3, 8, 9, 21, 22, ácido trigaloilquínico (29), 30a e 30b (Guilhon-Simplício, et al., 2017; Figura 2).

No extrato hidroetanólico das frutas de $B$. cydoniifolia foram identificadas as substâncias 1a, 1b, 5, 8, isoquercetrina (12), resveratrol (26), trans-piceatanol (27), procianidina (28), ácido dihidroxi-hexadecanoico (36), hexosil-O-C8H16O2, hexosil-O-hidroxihexanoato e um derivado do ácido málico e do ácido quínico (Santos, et al., 2007; Figura 2).

Na maioria dos estudos químicos realizados com espécies pertencentes ao gênero Byrsonima observa-se o isolamento de polifenóis, em especial dos flavonoides (Sannomiya, et al., 2007; Saldanha, et al., 2016; Souza, et al., 2017; GuilhonSimplício, et al., 2017). Na planta, os flavonoides exercem inúmeras funções nas plantas, isto é, protegem contra raios ultravioleta, contra insetos, fungos, vírus, bactérias e a capacidade de atração de animais polinizadores (Santos \& Rodrigues, 2017). Além disso, várias atividades farmacológicas tem sido relacionadas aos polifenóis, dentre estas se destacam a atividade antioxidante (Belisário, et al., 2020; Souza, et al., 2017; Silva, et al., 2019; Verdam, et al., 2017; Guilhon-Simplicio, et al., 2017; Pereira, et al., 2015; Vargas, et al., 2016; Santos, et al., 2017; Santos, et al., 2019; Souza-Melo, et al., 2021), antiinflamatória (Saldanha, et al., 2016(a); Saldanha, et al., 2016(b); Verdam, et al., 2017; Guilhon-Simplicio, et al., 2017; Santos, et al., 2019; Moreira, et al., 2011) e analgésica (Verdam, et al., 2017; Orlandi, et al., 2011). 
Figura 2. Substâncias isoladas do gênero Byrsonima.

(1)<smiles>O=C(O)C1(O)CC(O)C(O)C(O)C1</smiles>

b galoil
(2)

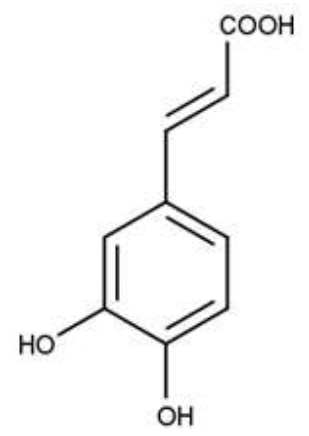

(3)<smiles>O=C(O)c1cc(O)c(O)c(O)c1</smiles>

(4)

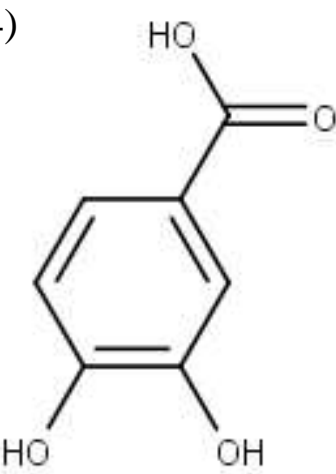

(5)<smiles>Oc1cc(O)c2c(c1)O[C@H](c1ccc(O)c(O)c1)[C@H](O)C2</smiles>

(9)<smiles>C[C@H]1OC(OC[C@H]2O[C@@H](Oc3c(-c4ccc(O)c(O)c4)oc4cc(O)cc(O)c4c3=O)[C@H](C)[C@H](O)[C@H]2O)[C@H](C)[C@@H](O)[C@@H]1O</smiles> 
(10)

(11)

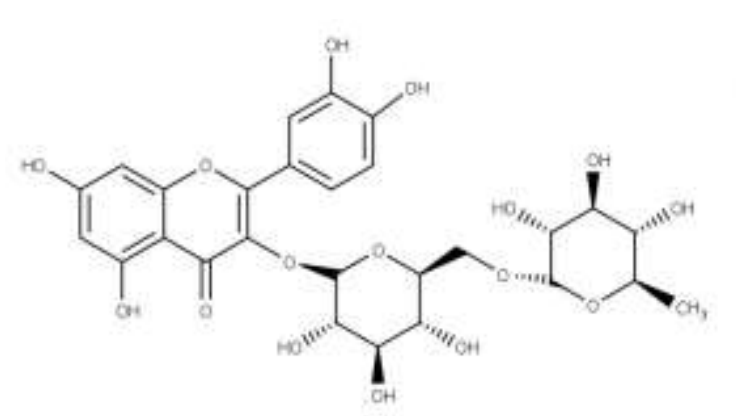

(14)

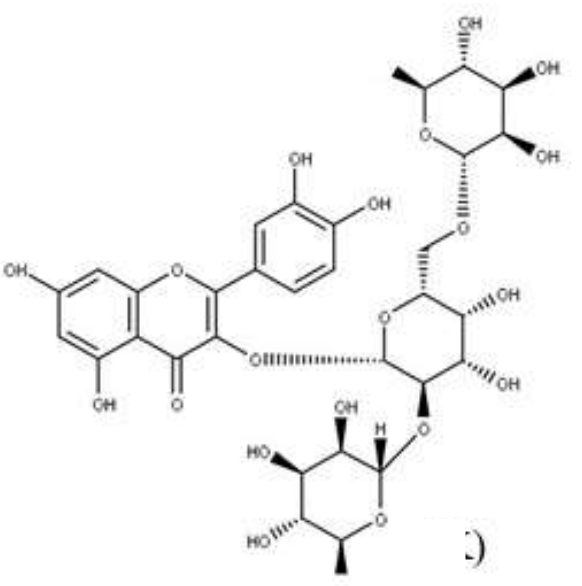

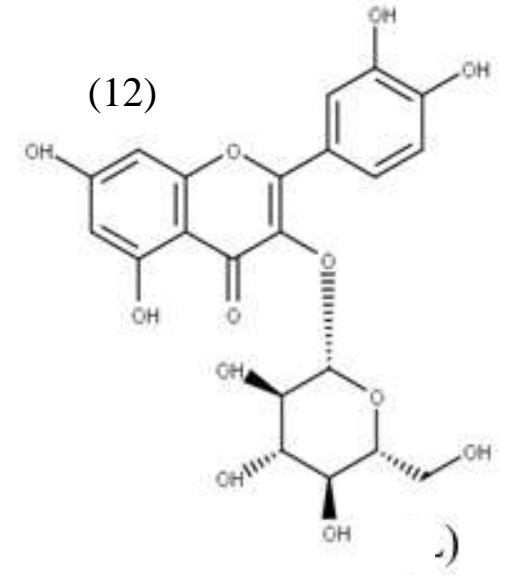

(16)

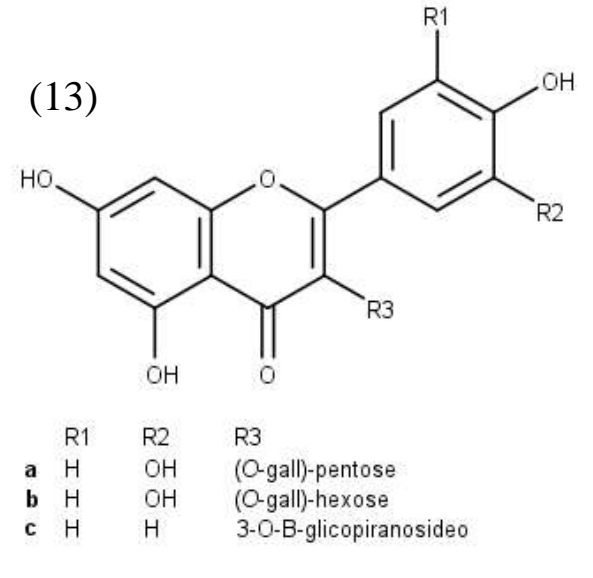

(17)<smiles>CC12CCC(O1)C(C)(C)CC2</smiles>

(15)
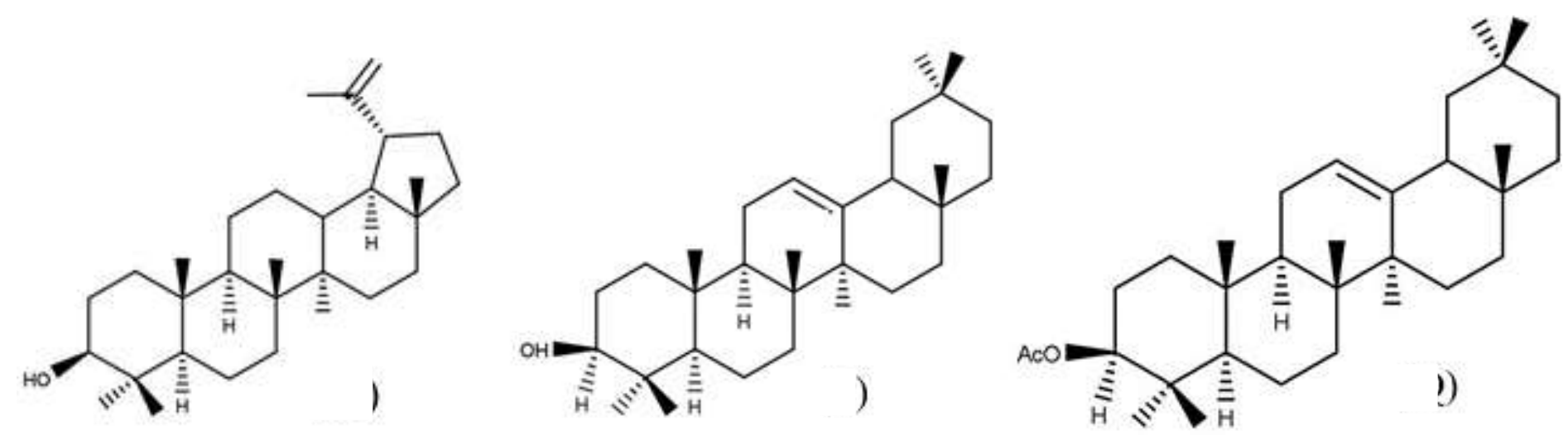


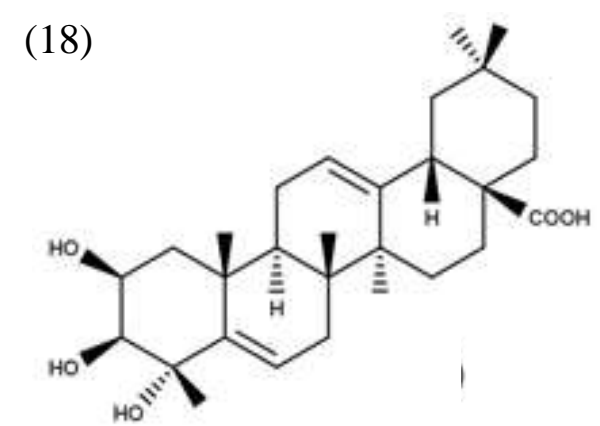

(22)<smiles>O=C1CC(c2ccc(O)cc2)Oc2cc(O)cc(O)c21</smiles><smiles>[194Os]</smiles><smiles>Oc1ccc(/C=C/c2cc(O)cc(O)c2)cc1</smiles>

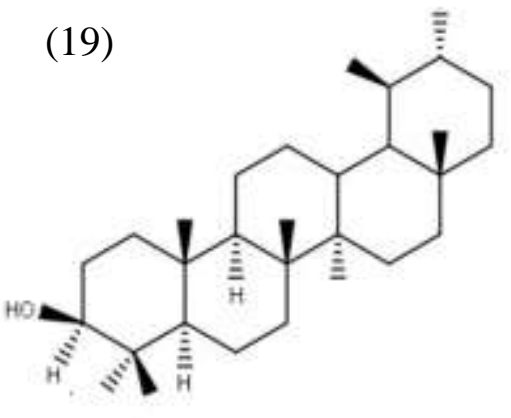

(23)

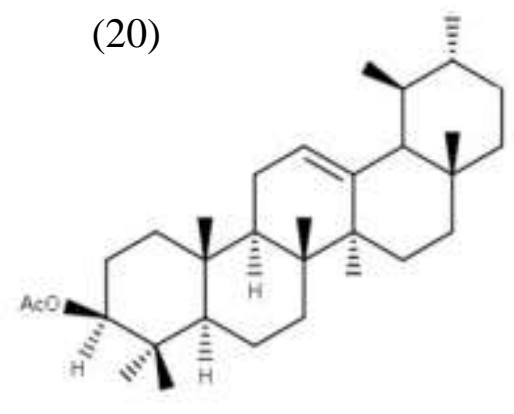

(24)<smiles>Oc1cc(O)c2c(c1)O[C@H](c1cc(O)c(O)c(O)c1)[C@H](O)C2</smiles>

(25)

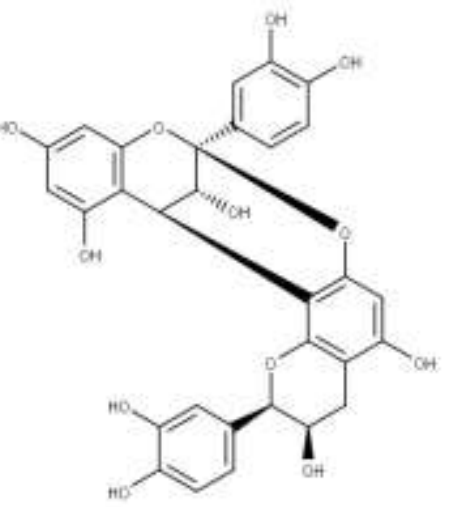<smiles>O=c1c(O)c(-c2ccc(O)cc2)oc2cc(O)cc(O)c12</smiles><smiles>COc1cc(-c2oc3cc(O)cc(O)c3c(=O)c2O)cc(O)c1O</smiles>

(27)<smiles>Oc1cc(O)cc(CCc2ccc(O)c(O)c2)c1</smiles>

(28)

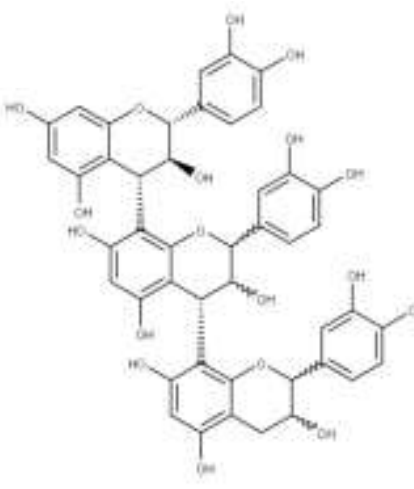

(29)




(30a)<smiles>C[C@@H]1Cc2c(O)cc(O)cc2O[C@H]1c1ccc(O)c(O)c1</smiles>

$(30 b)$<smiles>Oc1cc(O)c2c(c1)O[C@H](c1ccc(O)c(O)c1)[C@H](O)C2</smiles>

$(31)$<smiles>COc1cc(C(=O)O)cc(OC)c1O</smiles>

(32)<smiles>Oc1cc(O)c2c(c1)O[C@H](c1ccc(O)c(O)c1)[C@H](O)C2</smiles>
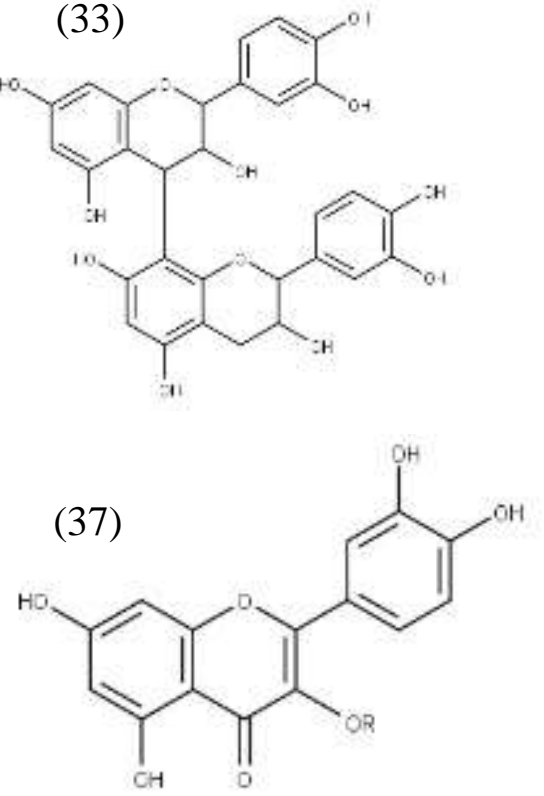

(36)<smiles>O=C1CC[C@@H](C(=O)O)N1</smiles>

a ${ }^{\mathrm{R}}$ : a. b 12 :- -gabit-AHat-aratinopiranos 1 deo
(38)

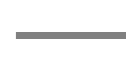<smiles>C1CCCCC1</smiles>

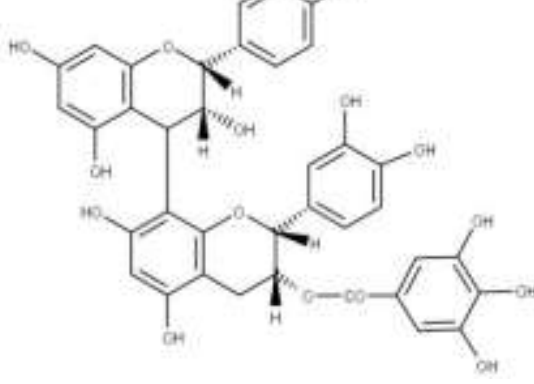

(39)

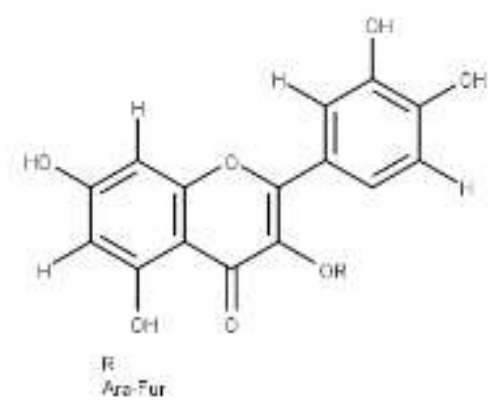

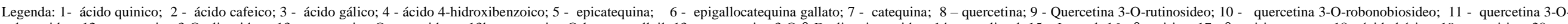

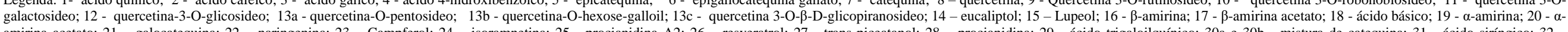

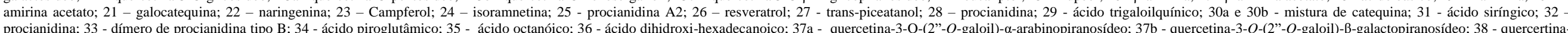
3-O-arabinosideo; 39 - protocianidina dimérica esterificada com o ácido gálico (B2-3"-O-galato). 


\subsection{Atividades farmacológicas}

\subsubsection{Atividade antioxidante}

$\mathrm{O}$ aparecimento de diversas patologias, principalmente de doenças crônicas está fortemente ligada ao desequilíbrio do balanço oxidativo e ao aumento da produção de espécies reativas de oxigênio, desencadeando processo denominado de estresse oxidativo (Souza-Junior, 2020). Diversas espécies possuem em suas características biológicas o potencial antioxidante, tais características estão associadas com a presença de compostos fenólicos, como catequinas, glicosídeos triterpênicos e outros flavonóides (Farias, 2017).

No estudo da atividade antioxidante da $B$. crassifolia, determinada através do método de eliminação do radical livre estável 1,1-difenil-2-picrilhidrazil (DPPH), demonstrou que o tempo de armazenamento da polpa da fruta interfere na atividade, havendo uma redução na capacidade antioxidante à medida em que se eleva o tempo de acondicionamento (Belisário, et al., 2020). Visando assegurar a qualidade da polpa de fruta é importante o armazenamento sob resfriamento, também demonstrou que o processo de pasteurização desses materiais vegetais tem o efeito oposto, mostrando menores valores para estes compostos antioxidantes (Arampath \& Dekker, 2019).

O extrato de folhas de $B$. crassifólia (BCP) e sua fração (BCF) contra o estresse oxidativo foi avaliada pela atividade do radical DPPH, a inibição da peroxidação de lipídios e a eliminação de radicais superóxidos produzidos no ensaio de quimioluminescência. No ensaio de DPPH, BCP e BCF apresentaram capacidade antioxidante, também inibiram a peroxidação dos lipídeos. No entanto, na eliminação de radicais superóxido BCP foi mais ativo (Souza, et al., 2017). A atividade antioxidante exibida tanto para $\mathrm{BCP}$ quanto para $\mathrm{BCF}$, principalmente a proteção contra peroxidação lipídica, pode estar relacionada ao alto teor de flavanol presente na espécie, que pode interagir com a membrana fosfolipídica, prevenindo que os agentes oxidantes acessem a bicamada lipídica e causem dano a membrana (Furlan, et al., 2015).

A capacidade antioxidante das frutas de B. stipulacea e de B. crassifolia foram avaliadas com a utilização dos ensaios de DPPH e o de capacidade de absorção do radical de oxigênio (ORAC). Os resultados demonstraram, em ambas análises, que B. crassifolia apresentou um maior potencial antioxidante que o B. stipulacea (Silva, et al., 2019). Estas diferenças na atividade antioxidante podem estar relacionadas as diferenças nas composições químicas entre a $B$. stipulacea $\mathrm{e}$ B. crassifolia. No entanto, ainda existem carências de estudos químicos para espécie B. stipulacea, sendo importante a realização deste estudo para a espécie.

Para o ensaio de atividade antioxidante de $B$. duckeana foi utilizado o DPPH, sendo as frações mais ativas a Fração Clorofórmica (FCL) e Fração Acetato de Etila (FAE). A FAE apresentou elevados teores de polifenóis, enquanto que a FCL o teor de polifenóis foi um pouco menor. A FAE possui elevadas concentrações de ácido gálico e associação com éster correspondente (Verdam, et al., 2017). Os polifenóis são considerados metabolitos mais ativos como antioxidantes, sendo a relação da concentração e atividade antioxidante o foco de vários estudos (Köksal, et al., 2016; de Souza, et al., 2016).

Os extratos das cascas dos caules de B. crispa, B. duckeana, B. garcibarrigae e B. incarnata foram avaliados por meio dos ensaios de DPPH (radical livre), ABTS (radical catiônico) e superóxido (radical aniônico). No teste de DPPH, apenas as amostras $B$ duckeana e $B$. incarnata apresentaram resultados equivalentes aos dos controles positivos utilizados. No teste de superóxido, todas as amostras apresentaram valores equivalentes aos controles positivos, com exceção da $B$. crispa. Já nos ensaios de ABTS todas as amostras foram estatisticamente equivalentes aos controles positivos, apresentando capacidade antioxidante que estão geralmente relacionadas aos flavonoides e outros compostos fenólicos presentes na planta (GuilhonSimplicio, et al., 2017).

Em outro estudo, avaliou a atividade antioxidante, através do ensaio de DPPH, de extratos das folhas (BCF) e galhos (BCG) de B. coccolobifolia. Os resultados mostraram o elevado potencial antioxidante do BCG e BCF (valores variando de 
41- 70\%), sendo estes extratos apresentaram os maiores teores de polifenóis (Pereira, et al., 2015). Outro estudo demonstrou uma correlação entre a capacidade antioxidante e o teor de compostos fenólicos (Clemes et al., 2015).

O extrato obtido das cascas do caule de B. japurensis foram submetidos a avaliação da atividade antioxidante utilizando seis métodos diferentes. No teste de DPPH, o extrato de B. japurensis foi um dos mais ativos, enquanto que no teste de eliminação de radicais ABTS, a espécie não se mostrou como uma das mais ativas, sendo sua $\mathrm{CI}_{50}>10 \mu \mathrm{g} / \mathrm{mL}$. Outro ensaio utilizado foi o radical ânion superóxido, o extrato de B. japurensis foi um dos que exibiram maior atividade na eliminação desses radicais. No método do oxigênio singlete, devido à coloração do extrato, houve interferência na análise. No teste de branqueamento de $\beta$-caroteno/linoléico, o extrato testado inibiu a oxidação do ácido linoléico. Acredita-se que os polifenóis totais, de forma geral, têm relação com os potenciais apresentados nos demais ensaios (Vargas, et al., 2016).

O extrato hidroetanólico das frutas de B. cydoniifolia, através do ensaio DPPH, apresentou capacidade antioxidante (Santos, et al., 2017). Os derivados fenólicos, juntamente com os flavonoides, presentes na espécie são responsáveis pela alta capacidade antioxidante observada no extrato, principalmente devido às suas propriedades redox e sua capacidade de neutralizar espécies reativas de oxigênio (Rubio et al., 2013), capacidade essa também associada com o conteúdo de fenol total (Li, et al., 2013) mostraram que existe uma correlação positiva entre a atividade antioxidante e o teor de fenol nas plantas (Santos, et al., 2017).

Em um outro estudo, a atividade antioxidante de duas frações de um extrato metanólico de $B$. intermedia foi avaliada através do teste determinação de glutationa (GSH). As frações Acetato de Etila (EtOAc) e a fração aquosa (AcoAq) aumentaram os níveis de GSH em diversos métodos aplicados (Santos, et al., 2019). O aumento de GSH é um fator importante no efeito antioxidante, pois é a molécula reativa capaz de promover proteção contra oxidação de DNA, lipídios e proteínas, impedindo assim, o efeito deletério de moléculas como peróxido de hidrogênio (David, et al., 2010).

O extrato etanólico de folhas de B. gardneriana (BGE) foi testado quanto à sua atividade antioxidante na presença de espécies reativas de oxigênio (ROS), sendo ativo em todas as concentrações testadas. Quando testado quanto ao seu potencial oxidante e antioxidante em eritrócitos humanos na presença de fenil-hidrazina com base na formação de metemoglobina, não demonstrou efeitos oxidantes em comparação com o controle positivo, nem apresentou atividade antioxidante na presença de fenil-hidrazina (Souza-Melo, et al., 2021). O segundo composto mais encontrado no BGE é o eucaliptol, composto esse já descrito na literatura com propriedades antioxidantes (Ciftci, et al., 2011) e pode estar relacionado a atividade BGE no ensaio de ROS.

De acordo com os estudos analisados, é possível compreender o elevado e promissor potencial das espécies de Byrsonima em relação a sua capacidade antioxidante. Sendo importante estudos que visem o aprofundamento desta atividade, bem como identificar os compostos responsáveis pela atividade antioxidante.

\subsubsection{Atividade anti-inflamatória e analgésica}

A atividade anti-inflamatórios do extrato metanólico das folhas de B.verbascifolia foi avaliada utilizando os modelos de edema de pata induzido por carragenina, recrutamento de neutrófilos induzido por carragenina e produção de óxido nítrico (NO) por macrófagos peritoneais. Este extrato, administrado por via intraperitoneal (ip), reduziu o edema da pata, a migração de neutrófilos para o peritônio e a produção de NO. Compostos fenólicos como catequinas (procianidinas), flavonoides e glicosídeos triterpênicos são os responsáveis pelas ações anti-inflamatórias devem ser mediadas, em parte, através da inibição da produção de NO.

Esse efeito parece ser mediado, pelo menos em parte, pela redução da síntese de TNF- $\alpha$ e, o pré-tratamento com em uma dose menor (12,50 mg/kg), exibiu um maior efeito inibitório na produção de TNF- $\alpha$ e PGE 2 durante a inflamação da pata (Tabela 3) (Saldanha et al, 2016 ${ }^{\text {b). }}$ 
O extrato metanólico das folhas de B. verbascifolia (BvME) foi submetido ao fracionamento, sendo obtidas as frações: hexânica, clorofórmica, acetato de etila e butanólica (BvBF). A BvBF foi submetida a avaliação de atividade antinociceptiva (contorção abdominal induzida por ácido acético, envolvimento do sistema opioidergico, formalina). Esta fração reduziu as contorções abdominais, sua ação no teste da formalina foi na fase 1. No ensaio do sistema opioidérgico, houve aumento do período de latência, sendo similar ao a morfina. No teste de toxicidade aguda, a dose letal $50 \%$ em $24 \mathrm{~h}$ foi de $889,834 \mathrm{mg} / \mathrm{kg}$. Apesar deste potencial efeito tóxico, parece que a fração não possui potencial teratogênico e mutagênico (Tabela 3) (Saldanha, et al, 2016a).

Os extratos aquosos de B. crispa, B. duckeana, B. garcibarrigae, e B. incarnata foram submetidos as avaliações das atividades anti-inflamatória in vitro, através do ensaio de indução por LPS dos macrófagos, e antinociceptiva (teste da formalina). O extrato de B. crispa reduziu a liberação de NO induzida por LPS e nenhuma interferência foi observada na produção de TNFa. O ensaio da formalina demonstrou que o extrato atuou na fase 1. Em relação ao extrato B. duckeana, observou redução na liberação de NO. Também, os extratos de $B$. garcibarriage e $B$. incarnata também reduziram a liberação de NO. B. garcibarrigae foi submetido ao ensaio da formalina (30 e $100 \mathrm{mg} / \mathrm{kg}$ ) mostrando-se ativos em 100 e $300 \mathrm{mg} / \mathrm{kg}$. Além disso, as espécies mostraram-se ativas em pelo uma fase da formalina e este efeito pode relacionado a elevadas concentrações de quercetina e/ou rutina (Tabela 3) (Guilhon-Simplicio, et al., 2017).

O extrato etanólico de B. duckeana foi submetido ao fracionamento, sendo obtidas as frações hexânica (FHx), clorofórmica $(\mathrm{FCl})$ e acetato de etila (FAE). O extrato foi submetido ao teste de peritonite induzida por carragenina, observando uma redução na migração de leucócitos para o local da inflamação e exsudato proteico. Extrato e frações foram submetidos a avaliação da atividade antinociceptiva através dos ensaios de contorção abdominal. Apenas a FAE foi submetida ao ensaio de placa quente e o extrato ao teste da formalina. O extrato, $\mathrm{FCl}$ e $\mathrm{FAE}$ reduziram o número de contorções abdominal, sendo a FAE mostrou efeito analgésico em todas as doses avaliadas. No ensaio da formalina demonstrou que o extrato atuou nas duas fases em dose muito elevada. As atividades da FAE podem estar relacionadas ao ácido galico (Verdam, et al., 2017). As atividades antioxidante e anti-inflamatória ácido gálico tem sido relatada (Lima Júnior, et al., 2021; Pereira, et al., 2021) e parece que a redução de espécies reativas de oxigênio está envolvida na atividade anti-inflamatória (Verdam, et al., 2017).

Em um outro estudo, o extrato aquoso (BiAE) e fração acetato de etila (EtOAc) das folhas de B. intermedia foram submetidos aos testes de edema de pata induzida por carragenina e teste de formação de tecido granulomatoso induzido por pellet de algodão. O BiAE não apresentou atividade anti-inflamatória nas doses avaliadas (30, 100 e 300mg/kg), entretanto houve uma redução significativa na formação do tecido granulomatoso. A EtOAc teve atividade significativa contra inflamação em dose de $100 \mathrm{mg} / \mathrm{kg}$, uma significativa redução na formação do tecido granulomatoso nos pellets de algodão implantados (Moreira, et al., 2011). 
Tabela 3: Classificação de método de análise em relação à espécie, amostra e resultados.

\begin{tabular}{lcll}
\hline Espécie & Amostra & Método & Resultado \\
\hline B. verbascifolia & EMF & Edema de pata; peritonite ${ }^{1}$ & Redução do edema e migração celular \\
\cline { 2 - 4 } & FBF & $\begin{array}{l}\text { Formalina; contorções abdominais e e } \\
\text { toxicidade }^{2}\end{array}$ & $\begin{array}{l}\text { Ação na fase um em formalina, redução de contorções } \\
\text { abdominais e dose letal 50\% em 24h de 889,834 }\end{array}$ \\
\hline B. crispa & EAC & Macrófagos induzido por LPS $^{3}$ & Redução da liberação de NO induzido por LPS \\
\hline B. duckeana & EAC & Macrófagos induzido por LPS $^{3}$ & Redução da liberação de NO induzido por LPS \\
\hline B. incarnata & EEC & Peritonite & Redução da migração de leucócitos \\
\hline B. garcibarrige & EAC & Macrófagos induzido por LPS $^{3}$ & Redução da liberação de NO induzido por LPS \\
\hline
\end{tabular}

EMF: extrato metanólico das folhas; FBF: fração butanólica das folhas; EEC: extrato etanólico da casca; EAC: extrato aquoso da casca; PEtOAc: fração acetato de etila; PAcoAq: Fração aquosa; LPS: lipopolissacarídeo. 1-Saldanha, et al., 2016 ; 2- Saldanha, et al., 2016aa; 3Guilhon-Simplicio, et al., (2017); 4- Verdam, et al., (2017).

\subsubsection{Outras atividades farmacológicas}

Do extrato metanólico das folhas de $B$. intermedia foi obtido duas frações, fração acetato de etila (EtOAc) e fração aquosa (AcoAq). As frações foram submetidos aos seguintes testes: ulceras gástricas induzidas por etanol, ulceras gástricas induzidas por anti-inflamatórios não esteroidais (AINES), lesões agudas gástricas induzidas por isquemia e reperfusão. No teste de ulceras induzidas por etanol observou-se redução no tamanho da ulcera em animais pré-tratados com as frações (100 e $200 \mathrm{mg} / \mathrm{kg}$ ). Enquanto que, no modelo de ulceras induzidas por AINES, apenas o pré-tratamento com AcoAq teve um efeito gastroprotetor, seguida da redução significativa da atividade de mieloperoxidase (MPO) e aumento de GSH. No teste de lesão induzida por isquemia e reperfusão, pré-tratados as frações, observou uma redução na extensão de lesão em $79 \%$ (EtOAc) e 73\% (AcoAq). Ainda foi avaliada a atividade contra Helicobacter pylori (ATCC 43504), através do ensaio da microdiluição. Foram obtidas MIC de >0,1000 mg / mL (AcoAq) e 0,500 mg / mL (EtOAc), sendo considerados inativos (Santos, et al., 2019).

As frações AcoAq e EtOAc foram avaliação aos ensaios de MPO, determinação de citocinas no tecido gástrico (TNF-alpha e IL-1 $\beta$ e IL-10), sendo os animais previamente tratados com as frações. O pré-tratamento com EtOAc quebra o ciclo vicioso que existe durante a Isquemia e Reperfusão. Durante a isquemia ocorre estresse oxidativa na mucosa gástrica, levando a um processo de injuria que é agravado no momento da reperfusão, liberando mais espécies reativas de oxigênio, mediadores pró-inflamatórios e quimiotaxia de células inflamatórias. O tratamento prévio com as frações reduz o estresse oxidativo e, consequentemente o processo inflamatório e parece que os flavonoides e ácidos fenólicos estão envolvidos nesta atividade (Santos, et al., 2019).

A atividade contra bactéria planctónica marinha e antibiofilme do extrato aquoso de folhas B. gardneriana. Este extrato não inibiu o crescimento destas bactérias, entretanto, este extrato inibiu a formação de biofilme cinco espécies de bactérias na concentração de $1 \mathrm{mg} / \mathrm{mL}$. Também, inibiu a formação de biomassa em até $98 \%$ em relação ao controle (Agostini, et al., 2019). Logo, estudos em bactérias patogênicas humanas que formam o biofilme devem ser feitos, visando identificar o potencial inibitório da espécie.

\subsubsection{Citotoxicidade}

Os extratos das folhas de B. correifolia, B. fagifolia, B. verbascifolia e B. intermedia foram submetidos a avaliação da citotoxicidade em células epitélio gástrico normal primário (GAS) e a de carcinoma hepatocelular (HepG2). Este extrato apresentou efeito citotoxicidade, utilizando o MTT, em concentrações $\geq 1,2 \mu \mathrm{g} / \mathrm{mL}$, em HepG2, sendo considerado tóxico. Resultado similar foi obtido no ensaio com vermelho neutro (HepG2= 2,4 e GAS=0,61 $\mu \mathrm{g} / \mathrm{mL}$ ), sendo mais tóxica para a linhagem normal. Para o lactato desidrogenase (LDH), em ambas as células a concentração citotóxica foi igual ou superior a 
4,8 $\mu \mathrm{g} / \mathrm{mL}$. Independente do ensaio realizado, observou-se que este extrato possui potencial citotóxico (Specian, et al., 2019).O extrato de B. fagifolia, em todos os métodos utilizados e ambas linhagens, apresentou uma citotoxicidade significativa para as linhagens GAS e HepG2. Também, o extrato de B. intermedia foi citotóxico para ambas a linhagens, no entanto, no ensaio de LDH observou maior efeito citotóxico para a linhagem HepG2. De modo similar as demais espécies, extrato de $B$. verbascifolia mostrou-se citotóxico para ambas linhagens (Specian, et al., 2016).

Os extratos etanólicos obtidos das folhas (EEFo), caule (EECa) e frutos (EEFr) B. sericea foram submetidos, sendo submetido a partição apenas o extrato das folhas (EEFo), obtendo-se as seguintes frações: metanol: água (FMA), acetato de etila (FAE), clorofórmica (FCL) e hexânica (FHX). A avaliação da citotoxicidade em células HepG2 e HL-60 demonstrou que o fracionamento reduziu a toxicidade, sendo a fração acetato etila menos tóxico para a maioria das linhagens (Tabela 4) (Silva, et al., 2016). Estudos que visem a caracterização química dos extratos e frações podem contribuir para compreensão destas diferenças no potencial citotóxico. Também, é importante realização de estudos que visem avaliar o potencial genotóxico e mutagênico destas frações.

Tabela 4: Citotoxicidade de Byrsonima sericea.

\begin{tabular}{lccccc}
\hline Amostras & \multicolumn{3}{c}{$\mathrm{CI}_{50}(\mu \mathrm{g} / \mathrm{mL}) \pm \mathrm{SD}$} & $\mathrm{K} 562$ & HL-60 \\
\cline { 2 - 6 } & PBMC & B16-F10 & HepG2 & ND & $25,27 \pm 8,79$ \\
EEFr & ND & ND & $25,03 \pm 5,24$ & ND & $27,32 \pm 0,06$ \\
EECa & ND & ND & $8,02 \pm 6,85$ & ND & $64,71 \pm 5,28$ \\
EEFo & ND & 13,46 & $21,84 \pm 2,64$ & $>50$ & $102,7 \pm 1,12$ \\
FMA & 33,81 & 17,44 & $91,16 \pm 0,64$ & $>50$ & $103,3 \pm 7,26$ \\
FAE & $>50$ & ND & $39,14 \pm 0,64$ & ND & $70,12 \pm 11,24$ \\
FCL & ND & 16,14 & $91,66 \pm 9,49$ & 28,32 & $109,0 \pm 2,52$ \\
FHX & 17,58 & &
\end{tabular}

Extratos etanólicos obtidos das folhas (EEFo), caule (EECa) e frutos (EEFr) B. sericea; frações metanol: água (FMA), acetato de etila (FAE), clorofórmica (FCL) e hexânica (FHX); células mononucleares do sangue periférico (PBMC); linhagem de células tumorais B16-F10 (melanoma de camundongo); HepG2 (carcinoma hepatocelular humano), K562 (leucemia mielocítica humana) e HL-60 (leucemia prómielocítica humana): ND: não determinado; $\mathrm{CI}_{50}$ : concentração inibitória 50\%. Fonte: Silva, et al., 2016 adaptado pelos Autores.

\section{Conclusão}

Diante da vasta literatura, a presente revisão buscou identificar quais as espécies de Byrsonima apresentavam estudos e quais seriam suas atividades encontradas. De forma que pudessem ser sintetizadas essas informações, facilitando o trabalho de possíveis futuras pesquisas. Os estudos químicos realizados com as diferentes espécies pertencentes ao gênero Byrsonima demonstraram a presença de compostos fenólicos, em especial flavonoides. Estes constituintes químicos, provavelmente, estão envolvidos nas atividades encontradas: antioxidante, anti-inflamatória e analgésica e várias vias de sinalizações devem estar envolvidas nestas atividades. Contudo, poucos foram os estudos realizados acerca da citotoxicidade das espécies pertencentes ao gênero, e esses poucos apresentaram um elevado potencial citotóxico sem nenhuma verificação de correlação com os compostos presentes nas espécies, fato bastante preocupante e que dificulta a utilização do gênero para fins terapêuticos. Desse modo, torna-se importante a realização de trabalhos que visem investigar as espécies do gênero Byrsonima em outros modelos in vitro e in vivo.

\section{Referências}

Agnihotri, S., Wakode, S. \& Agnihotri A. (2010). An overview on anti-inflammatory properties and chemo-profiles of plants used in traditional medicine. IJNPR., 1(2),150-167. 10.1080/13880200500301720.

Agostini, V., Macedo, A., Muxagata, E., Silva, M. \& Pinho, G. (2020). Non-toxic antifouling potential of caatinga plant extracts: effective inhibition of marine initial biofouling. Hydrobiologia, 847(1), 45-60. 10.1007/s10750-019-04071-6.

Alexandrino, V., Sousa, J. \& Bastos, M. (2011). Estudo taxonômico da família Malpighiaceae Juss. das restingas de Algodoal/Maiandeua, Maracanã, Pará, Brasil. Bol. Mus. Para. Emilio Goeldi Cienc. Nat, 6(3), 335-347. 
Almeida, L.F.R., et al., (2007). In vitro allelopathic effects of extracts and amenthoflavone from Byrsonima crassa (Malpighiaceae). Journal of Plant Interactions, 2(2), 121- 124. 10.1080/17429140701561483.

Arampath, P. C. \& Dekker, M. (2019). Bulk storage of mango (mangifera indica 1.) And pineapple (ananas comosus 1.) Pulp: effect of pulping and storage temperature on phytochemicals and antioxidant activity. Journal of the Science of Food and Agriculture., 30(99), 5157-5167. 10.1002/jsfa.9762.

Barros, M. (2012). Preparação de novos derivados flavonóides com potencial atividade biológica [Dissertação de Mestrado]. Estudo Geral - Repositório científico da Universidade de Coimbra. http://hdl.handle.net/10316/26132.

Belisário, C., et al. (2020). Carotenoids, sugars, ascorbic acid, total phenolics, and antioxidant activity of murici from brazilian cerrado during refrigerated storage. Ciencia rural, 50(4), 1-8. 10.1590/0103-8478cr20180620.

Bonacorsi, C., et al., (2013). Comparison of Brazilian Plants Used to Treat Gastritis on the Oxidative Burst of Helicobacter pylori-Stimulated Neutrophil. Evidence-Based Complementary and Alternative Medicine, 2013, 8. 10.1155/2013/851621.

Cho, S. Y., et al. (2003). Quercetin suppresses proinflammatory cytokines production through MAP kinases and NF-kappa B pathway in lipopolysaccharidestimulated macrophage. Mol Cell Biochem., 243, 153-160. 10.1023/a:1021624520740.

Ciftci, O., Ozdemir, I., Tanyildizi, S., Yildiz, S., \& Oguzturk, H. (2011). Antioxidative effects of curcumin, $\beta$-myrcene and 1,8-cineole against 2,3,7,8tetrachlorodibenzo-p- dioxin-induced oxidative stress in rats liver. Toxicology and Industrial Health, 27(5), 447-453. 10.1177/0748233710388452.

Clemes, S., Beirith, A. \& Zeni, A. (2015). Avaliação de polifenóis e capacidade antioxidante de seis espécies da Mata Atlântica. Scientia Plena, $11,051001$.

Cruz, L., Almeida, M. \& Dolabela, M. (2020). Contributions of complementary therapies and other strategies to the treatment of schizophrenia: an integrative review. Research, Society and Development, 9(11), e76791110376. 10.33448/rsd-v9i11.10376.

Cunha, W.R., et al., (2009). Screening of plant extracts from the Brazilian Cerrado for their in vitro trypanocidal activity. Pharmaceutical Biology, 47(8), 744749. 10.1080/13880200902951361.

Da Silva, A., Spricigo, P., Purgatto, E., Alencar, S. \& Jacomino, A. (2019). Volatile compounds determined by SPME-GC, bioactive compounds, in vitro antioxidant capacity and physicochemical characteristics of four native fruits from south america. Plant foods for human nutrition, 74(3), 358-363. $10.1007 / \mathrm{s} 11130-019-00745-7$.

David, C., David, J., Bahia, M. \& Aguiar, R. (2010). Métodos Para Determinação de Atividade Antioxidante In Vitro em Substratos Orgânicos. Química Nova., 33(10), 2202-2210. 10.1590/S0100-40422010001000033.

Farias, B., Fernandes, S., Santos, A., Souza, S. \& Souza, B. (2017). Estudo fitoquímico e análise de fotoproteção dos extratos eóleos essenciais de aniba canelilla (h.b.k) mez. The Journal of Engineering and Extract Sciences., 3(4), 0614-0620. doi.org/10.18540/jcecvl3iss4pp0614-0620.

Furlan, A., Jobin, M., Pianet, I., Dufourc, E. \& Géan, J. (2015). Flavanol/lipid interaction: a novel molecular perspective in the description of wine astringency $\&$ bitterness and antioxidant action. Tetrahedron, 71, 3143-3147. 10.1016/j.tet.2014.07.106.

Guilhon-Simplicio, F. \& Pereira, M. (2011). Aspectos químicos e farmacológicos de Byrsonima (Malpighiaceae). Química Nova, 34(6), 1032-1041. 10.1590/S0100-40422011000600021.

Guilhon-Simplicio, F. et al. (2017). Chemical composition and antioxidant, antinociceptive, and anti-inflammatory activities of four amazonian Byrsonima species. Phytptherapy Research., 31(11), 1686-1693. 10.1002/ptr.5884.

Higuchi, C.T., et al., (2011). Byrsonima fagifolia Niedenzu Apolar Compounds with Antitubercular Activity. Evidence-Based Complementary and Alternative Medicine, 2011, 5 .

Kim, H. P., Son, K. H., Chang, H. W. \& Kang, S. S. (2004). Anti-inflammatory plant flavonoides and cellular action mechanisms. Journal of Pharmacological Sciences, 96(3), 229-245. 10.1254/jphs.crj04003x.

Koksal, E., et al., (2016) Antioxidant activity and polyphenol content of Turkish thyme (Thymus vulgaris)monitored by liquid chromatography and tandem mass spectrometry. International Journal of Food Properties, 20(3), 514-525. 10.1080/10942912.2016.1168438.

Li, S., Li, S.-K., Gan, R.-Y., Song, F.-L., Kuang, L., \& Li, H.-B. (2013). Antioxidantcapacities and total phenolic contents of infusions from 223 medicinal plants. Industrial Crops and Products, 51, 289-298. 10.1016/j.indcrop.2013.09.017Lima, J. P., Franco, R. R., Saraiva, A. L. et al. (2021). Anacardium humile St. Hil as a novel source of antioxidant, antiglycation and $\alpha$-amylase inhibitors molecules with potential for management of oxidative stress and diabetes. Journal of Ethnopharmacology, 268, 1-12. 10.1016/j.jep.2020.113667.

Machelska, H., Labuz, D., Przewlocki, R. \& Przewlocka, B. (1997). Inhibition of nitric oxide synthase enhances antinociception mediated by mu, delta and kappa opioid receptors in acute and prolonged pain in the rat spinal cord. Journal of Pharmacology and Experimental Therapeutics, $282(2), 977-84$.

Moraes, W. P. (2011). Caracterização do mecanismo de ação antiinflamatória do flavonóide BAS1 isolado da planta Brosimum acutifolium [PublishedVersion, Universidade Federal do Pará]. http://repositorio.ufpa.br/jspui/handle/2011/2876.

Moreira, L.Q., et al., (2011). Anti-inflammatory effect of extract and fractions from the leaves of Byrsonima intermedia A. Juss. in rats. Journal of Ethnopharmacology, 138(2), 610-615. 10.1016/j.jep.2011.10.006.

Orlandi, L., et al., (2011). Anti-inflammatory and antinociceptive effects of the stem bark of Byrsonima intermedia A. Juss. Journal of Ethnopharmacology, 137(3), 1469-1476. 10.1016/j.jep.2011.08.032.

Peraza-Sánchez, S. R., Poot-Kantún, S., Toores-Tapia, L. W., May-Pat, F., Simá-Polanco, P., \& Cedillo-Rivera, R. (2005). Screening of Native Plants from Yucatan for Anti-Giardia lamblia. Activity. Pharmaceutical biology, 43(7), 594-598. 10.1080/13880200500301720. 
Pereira, A., Shitsuka, D., Pereira, F. \& Shitsuka, R. (2018). Scientific research methodology. [eBook]. Santa Maria: UAB / NTE / UFSM.

Pereira, J., Martins, A., Franca, M., Cavalcante, S. \& Feitosa, C. (2021). Espécies medicinais do Brasil com potencial anti-inflamatório ou antioxidante: Uma revisão. Society and Development, 10(7), e10310716196. 10.33448/rsd-v10i7.16196.

Pereira, V., Borel, C. \& Silva, R. (2015). Phytochemical screening, total phenolic content and antioxidant activity of Byrsonima species. Nature Product Reseach. 29(15), 1461-1465. 10.1080/14786419.2014.1002407.

Polanco-Hernández, G., et al., (2012). In vitro and in vivo trypanocidal activity of native plants from the Yucatan Peninsula. Parasitol Res., 110(1), 31-35. $10.1007 / \mathrm{s} 00436-011-2447-8$.

Ribeiro, V., Arruda C., El-Salam, M., \& Bastos, J. (2018). Brazilian medicinal plants with corroborated anti-inflammatory activities: a review. Pharmaceutical Biology., 56(1), 253-268. 10.1080/13880209.2018.1454480.

Robak, J., Shridi, F., Wolbis, M. \& Krolikowska, M. (1998). Screening of the influence of flavonoids on lipoxygenase and cyclooxygenase activity, as well as on nonenzymic lipid oxidation. Polish Journal of Pharmacology and Pharmacy, 40(5), 451-458.

Rubio, L., Motilva, M. J., \& Romero, M. P. (2013). Recent advances in biologicallyactive compounds in herbs and spices: A review of the most effectiveantioxidant and anti-inflammatory active principles. Critical Reviews in Food Science and Nutrition, 53(9), p.943-953. $10.1080 / 10408398.2011 .574802$.

Saldanha, A. \& Soares, A. (2015). Compostos químicos e aspectos botânicos, etnobotânicos e farmacológicos da Byrsonima verbascifolia Rich ex. A. Juss. Revista Brasileira de Plantas Medicinais. 17(4), 1000-1006. 10.1590/1983-084X/14_133.

Saldanha, A., et al (2016a). Anti-inflammatory effects of the butanolic fraction of byrsonima verbascifolia leaves: mechanisms involving inhibition of tumor necrosis factor alpha, prostaglandin e 2 production and migration of polymorphonuclear leucocyte in vivo experimentation. International immunopharmacology, 31, 123-131. 10.1016/j.intimp.2015.12.031.

Saldanha, A., et al (2016b). Chemical composition and anti-inflammatory activity of the leaves of Byrsonima verbascifolia. Journal of Natural Medicines., 70(4), 760-768. 10.1007/s11418-016-1011-3.

Saldanha, A., et al (2017). Peripheral and central antinociceptive effects of the butanolic fraction of Byrsonima verbascifolia leaves on nociception-induced models in mice. Inflammopharmacology, 25(1), 81-90. 10.1007/s10787-016-0300-5.

Sannomiya, M., et al., (2007). Mutagenic evaluation and chemical investigation of Byrsonima intermedia A. Juss. leaf extracts. Journal of Ethnopharmacology, 112(2), 319-326. 10.1016/j.jep.2007.03.014.

Santos, D. \& Rodrigues, M. (2017). Atividades farmacológicas dos flavonoides: um estudo de revisão. Estação Científica (UNIFAP)., 7(3), 29-35. 10.18468/estcien.2017v7n3.p29-35.

Santos, R., et al. (2019) Byrsonima intermedia a. Juss partitions promote gastroprotection against peptic ulcers and improve healing through antioxidant and anti-inflammatory activities. Biomedicine \& pharmacotherapy, 111, 1112-1123. 10.1016/j.biopha.2018.12.132.

Santos, V., et al. (2017). Nutraceutical potential of byrsonima cydoniifolia fruits based on chemical composition, anti-inflammatory, and antihyperalgesic activities. Food chemistry, 237, 240-246. 10.1016/j.foodchem.2017.05.082.

Silva, A., et al., (2019). Volatile Compounds Determined by SPME-GC, Bioactive Compounds, In vitro Antioxidant Capacity and Physicochemical Characteristics of Four Native Fruits from South America. Plant Foods for Human Nutrition, 74(3), 358-363. 10.1007/s11130-019-00745-7.

Silva, T., et al. (2016). Cytotoxic potential of selected medicinal plants in northeast Brazil. BMC Complementary and Alternative Medicine, 16(199), 1-9. 10.1186/s12906-016-1166-1.

Souza, F., et al. (2020). Aniba canelilla (kunth) mez (lauraceae): a review of ethnobotany, phytochemical, antioxidant, anti-inflammatory, cardiovascular, and neurological properties. Front. Pharmacol. 11(699), 1-14. 10.3389/fphar.2020.00699.

Souza, G., et al. (2016). Phenolic and aroma compositions of pitomba fruit (Talisia esculentaRadlk.) assessed by LC-MS/MS and HS-SPME/GC-MS. Food Research International, 83, 87-94. 10.1016/j.foodres.2016.01.031.

Souza, R. O., et al., (2017). Byrsonima crassifolia extract and fraction prevent UVB-induced oxidative stress in keratinocytes culture and increase antioxidant activity on skin. Industrial Crops \& Products, 108, 485-494.

Souza-Melo, W. O., et al., (2021). Phytochemistry, antifungal and antioxidant activity, and cytotoxicity of Byrsonima gardneriana (A. Juss) extract. Archives of Oral Biology, 123, 1-10. 10.1016/j.archoralbio.2020.104994.

Specian, A., et al. (2016). Ldh, proliferation curves and cell cycle analysis are the most suitable assays to identify and characterize new phytotherapeutic compounds. Cytotechnology, 68(6), 2729-2744. 10.1007/s10616-016-9998-6.

Taofiq, O., et al. (2016). A importância dos ácidos fenólicos na atividade anti-inflamatória de cogumelos comestíveis. In Encontro com a Ciência e Tecnologia em Portugal. Lisboa.

Vargas, F., et al (2016). Antioxidant activity and peroxidase inhibition of amazonian plants extracts traditionally used as anti-inflammatory. Bmc complementary and alternative medicine, 16(1), 1-8. 10.1186/s12906-016-1061-9.

Verdam, M. et al. (2017). Analgesic, anti-inflammatory, and antioxidant activities of Byrsonima duckeana w. R. Anderson (malpighiaceae). Scientific World Journal, 2017, 1-8. 10.1155/2017/8367042. 